\title{
IS GENERAL SCIENCE DESTINED TO GO DOWN INTO THE JUNIOR HIGH SCHOOL? IF SO, WHAT WILL BE - THE CONTENT OF THE COURSE? 1
}

\author{
By John C. Hessliz, \\ Knox College, Galesburg, Ill.
}

When one has the task of answering a double question, like the one just read, by a double-horned prophecy, he feels very much like answering the first question in the negative, and thereby avoiding the necessity of answering the second at all. To answer the questions named, in a manner at all adequate, would require an extended consideration of the meaning of the Junior High School and an equally elaborate discussion of the meaning of General Science. The first part of the question means, presumably, this: "If the High School organization and curricula are divided into those of the Junior High School and those of the Senior High School, will General Science be found in the Junior High School? If by the Junior High School we mean the usual seventh, eighth, and ninth years, the answer to the question is undoubtedly: "Yes." I feel quite certain of this answer in spite of the fervid attempts made a few years ago to swing educational public opinon over to a two-year General Science program for the four-year High School. In my judgment this movement has not succeeded, and will not succeed, unless by $a$ two-year program in General Science we mean to include a year of General Science and a year of Biology, each being run half time for two years as a split course. The fact remains that for the three-year Senior High School a year each of some Biological Subject, of Chemistry, and of Physics are the rule, and will continue to be the rule. The War placed an unusual stress upon the Physical Sciences, especially Chemistry; this stress, if there were no other causes, will usually reserve the last two HighSchool years for these sciences, during many decades to come. As a rule, the first year's work of the four-year High School will be some Introductory Science of a general, rather than of a specific character, and the second year's work will be some form of Biology, pure or applied. In the country districts the Biology work will be essentially agricultural in character.

Now as to the content of the General Science course, whether the course be given in the last year of the Junior High School or in the first year of the four-year High School. If one were to believe all he hears, in these strenuous days of controversy, he would conclude that the important thing about General

\footnotetext{
IRead before the General Science Sections of the C. A. S. and M. T. at St. Louia, Nov. 25, 1921.
} 
Science at the present time is not its content, not what it may accomplish for the pupil and the community, but the method by which it is to be taught. This is only a part, of course, of the age-long contest as to whether it is better to have something to teach, or to have a method of teaching. Of this dilemma I desire to take neither horn. Everyone knows that some teachers are helped by being compelled to follow some set method of work; it is equally true that many teachers are wrecked, as vital forces in the school and community, by too much methodology. One must choose sometimes, and the choice will depend upon a number of considerations, but chiefly upon the character and aptitudes of the teacher. What is important is, first, that the pupil shall be interested in Science, that he shall ask questions concerning the world about him, including the community of which he is a part. A second result, of equal importance with the first, is that the pupil shall be in a better position, after studying General Science, to answer his own questions, or, at any rate, to know, in a small way, to what source he ean go for the answer. Some teachers can accomplish this result by one method, some by another. The tragedy of General Science, as it is for all science, is that in too many cases the subject must be taught by teachers who are not really interested in Science at all, or no more interested than in any other subject of the curriculum. For these no method is of mueh value.

The object of General Science instruction is, as has been stated, the interesting of the pupil in his world and its phenomena. It is desirable for the pupil to have this interest in order chat he may realize how dependent he is upon natural law, and how much the knowledge of the laws of nature will benefit him in his life work and as a member of the community. This interest should carry him into some of the special sciences. It is the fashion in some General Science quarters to decry the relation of General Science to the later, special sciences. Let the course be sufficient unto itself, is the demand. To a certain extent it is true, of course, that the topics in General Science need not be selected as if the course were merely a preparation for the work of some subsequent year. But in a larger sense the course is a preparation, and should be held accountable for having accomplished something more or less tangible. $I t$ is far from the idea of those who pioneered in Introductory Science to ask nothing from the course but a study in methods. If the pupil leaves the educational system at the close of the ninth 
year, he should have the rudiments, at least, of the great, general, scientific ideas. This is what General Science will mean to him. If the pupil continues his work into the later years of the High School, or into the Senior High School, the course should have shown him the importance of Science, and shouid predispose him to the election of Biology, Physics, or Chemistry, to say nothing of some of the other sciences, such as Physiography, Geology, or Zoology. In a large sense General Science is a preparation, and cannot be treated as though it were sufficient unto itself.

What is true of General Science in the four-year High School is true, mutatis mutandis, in the Junior High School, if the educational system provides this latest subdivision of High Sehool organization. The organization of Junior High Schools, no matter what transcendent reasons may be found for them at this day, was primarily an economic one. Instead of building a new High Sehool whenever the growing High School population burst out of its too-small quarters, it was the habit for many years to rent old houses or apartments in the neighborhood and there to house the greater part, if not the whole, of the first-year High School class. This policy, like all temporary expedients, finally reached its limit here and there, and the public decided to tax itself for a new building. But what sort of a building? In our large centers of population, with the great increase of family means, and the constant effort on the part of the school authorities to stimulate attendance by the introduction of Commercial, Home Eeonomics, Industrial and similar courses, the race between school population and school rooms has been an unending one, with the result never in doubt. The new building was built for the overflow, which was the first-year class; then, as the upper grades were also crowded, some of the seventh and eighth grade pupils were sent over to the Junior, or Intermediate, High School building. When this synthesis of the seventh, eighth, and ninth years had been accomplished in a few places, schoolmen saw the opportunity presented, and the question of a unified curriculum for these grades became one of living interest. The end is not yet. As newer reasons for the formation of Junior High Schools, we have the following:

(1) They are a device for holding pupils in the school system during years of great student mortality, and of carrying these students over into the Senior High School, or, at any rate, of keeping them in school for one additional year. 
(2) In the Junior High School provision can be made for instruction hitherto very difficult, or nearly impossible, in the grade schools. Included in this type of instruction is laboratory work in Science, Househoid Science, and the Manual Arts. The laboratory facilities provided need not be as elaborate as if they were in the four-year High School, with its more formal science courses.

(3) The teachers of the Junior High School may be upon a lower salary scale than if they were in the four-year High School. This follows from the fact that teachers of essentially seventh and eighth grade training may be employed instead of the college graduate now demanded by the best High Schools. This question came to College Entrance Committees in an acute form, some years ago, when they were confronted with algebra courses which were presented for college entrance, and which had to be considered as a preparation for College Algebra, but had been taken in the eighth grade of the grammar school, along with the three R's.

(4) As a fourth reason for the Junior High School we have the argument that in such an organization the special-subject teacher can ultimately be employed in the place of the room teacher. This argument has already been stated in another form.

Without going farther into the history of the Junior High School or similar types of organization, let us consider what the General Science course should be. The question assigned me includes this; but from a prophecy of the future I insist that I must be excused. I will content myself with a place among fallible mortals, and state only what I think the Science course should be. Part of what the course in General Seience should be has emerged from the discussion that has already been presented.

(1) The course should have an experimental basis. This is true whether the instruction is by the Project Method, so called, or by the usual Deducto-Inductive method.

(2) The course should require study, reading and recitation, with some small residue left at the end of the semester or year as an increment of the student's knowledge.

(3) The course in General Science should lead the student to inquire regarding phenomena and the common practices of his community and to make a beginning, at least, of distinguishing causes from their effects.

(4) The student should be sufficiently interested in Science 
to desire to study some of the special sciences of the later years.

First, as to the experimental basis of Introductory Science. The best way, in my opinion, is to have the pupil carry on experimental work for himself. This work need not be as ambitious, by a great deal, as the laboratory courses of the Senior High School, but they should encourage the pupil to see that real experimention is not a matter of flasks and beakers and condensers of a special shape and label, but a question put to nature, either for the sake of just knowing what nature's answer will be, or for the sake of deciding a difference of opinion. One of the sad things about laboratory work, whether in Junior High School, Senior High School, or College, is the small space left for the gratification of that natural curiosity which is the primitive endowment of man, and which has borne him onward in his struggle for a worthwhile civilization. Our ideal seems to be embodied in some lines of Tennyson's, although we have twisted them in a manner which I am sure Tennyson never intended:

"Theirs not to reason why;

Theirs but to do."-

and be marked upon the doing.

While advocating individual experimentation in the school laboratory, if possible, I am well aware that this is impossible, and perhaps even undesirable, in some cases. Under such circumstances, certain types of home experimentation are possible, especially if the pupil who has carried out an experiment in a significant manner at home, brings the apparatus to the classroom and performs the experiment there. The student should by all means be encouraged to try out his ideas with apparatus, if this is feasible, and if he can do so without danger. If he cannot do this at home, or in a set laboratory, he can often carry it out in class as a part of some demonstration by the teacher. Right here I wish to protest against long-range demonstrations or lectures. The fact is that the words of wisdom emanating from a lecturer's or demonstrator's desk, in circles far above the Junior High School, in point of the age of the pupil, do not get very far from the aforesaid desk. This is especially true of a demonstration with clear glass apparatus. All details of such apparatus may be blurred to the pupil at the back of the room, and that which the pupil sees may be totally different from that which he is supposed to see. If demonstrations must take the place of individual experimentation, in Junior High School 
courses in General Science, the class should by all means be small, and the demonstration sufficiently informal, so that the pupils can come near the lecture table to see what is going on, and to get a bit, at least, of the "feel" of the apparatus.

As has already been said, the methods of instruction may vary, but the purpose of the General Science course must be substantially the same, whether the course is given in the Junior High School or in the four-year High School. The understanding of the world about him is what the pupil needs. In his life experience the pupil will get more of the "practical" and "commercial" than he will of the cultural, which is, after all has been said, the fundamental. Therefore, the science courses should give him some basic knowledge of those phenomena and laws which, for special purposes, we call physical, chemical, and biological. These are the only sure foundations for a sane study of the future, whether of practical subjects or of further eultural studies. This is true likewise for the growing knowledge which will come even to those whose means or condition render further schooling of the formal sort impossible. Science study is a sane preparation for a sane State.

\section{THE SCIENTIFIC CURRICULA IN HIGH SCHOOLS AND THE TEACHING OF DISEASE PREVENTION. ${ }^{1}$}

By Clarence W. East, M. D.

Department of Health, Springfield, Ill.

The scientific curricula in high schools vary within fairly definite limits. Sangamon County, Illinois is taken as a representative county, presenting urban, small town and country conditions. It has one city of 60,000 inhabitants and numerous towns of from less than 100 to 2,000 population. It presents an industrial, an agricultural and a mining community, each on a large scale.

Its high schools are those of a capitol city and a number of township high schools. We may assume that its high school curricula are representative.

The sciences taught are physics, chemistry, general sciences, meaning botany and zoology, and household sciences. By the latter is comprehended the selection and cooking of food stuffs and the selection and construction of simple garments for women and children. For the sake of being comprehensive we may add to this list physical culture and athleties.

\footnotetext{
1Regd before the Biology Sections of the C. A. S. \& M. T. Soldan High Sehool, St. Louis, Nov, 25, 1921.
} 